\title{
Pathfinder: open source software for analyzing spatial
}

\section{navigation search strategies [version 1; peer review: 2}

\section{approved]}

\author{
Matthew B. Cooke (iD1,2, Timothy P. O'Leary 1,2, Phelan Harris'1,2, Richard E. Brown³, \\ Jason S. Snyder (iD) 1,2 \\ ${ }^{1}$ Department of Psychology, University of British Columbia, Vancouver, British Columbia, V6T 1Z4, Canada \\ 2Djavad Mowafaghian Centre for Brain Health, University of British Columbia, Vancovuer, British Columbia, V6T 1Z3, Canada \\ ${ }^{3}$ Psychology and Neuroscience Department, Dalhousie University, Halifax, Nova Scotia, B3H 4R2, Canada
}

\begin{tabular}{l}
\hline V1 First published: 28 Aug 2019, 8:1521 \\
https://doi.org/10.12688/f1000research.20352.1 \\
Latest published: 15 Jun 2020, 8:1521 \\
https://doi.org/10.12688/f1000research.20352.2 \\
\hline
\end{tabular}

\section{Abstract}

Spatial navigation is a universal behavior that varies depending on goals, experience and available sensory stimuli. Spatial navigational tasks are routinely used to study learning, memory and goal-directed behavior, in both animals and humans. One popular paradigm for testing spatial memory is the Morris water maze, where subjects learn the location of a hidden platform that offers escape from a pool of water. Researchers typically express learning as a function of the latency to escape, though this reveals little about the underlying navigational strategies. Recently, a number of studies have begun to classify water maze search strategies in order to clarify the precise spatial and mnemonic functions of different brain regions, and to identify which aspects of spatial memory are disrupted in disease models. However, despite their usefulness, strategy analyses have not been widely adopted due to the lack of software to automate analyses. To address this need we developed Pathfinder, an open source application for analyzing spatial navigation behaviors. In a representative dataset, we show that Pathfinder effectively characterizes the development of highly-specific spatial search strategies as male and female mice learn a standard spatial water maze. Pathfinder can read data files from commercially- and freelyavailable software packages, is optimized for classifying search strategies in water maze paradigms, and can also be used to analyze 2D navigation by other species, and in other tasks, as long as timestamped xy coordinates are available. Pathfinder is simple to use, can automatically determine pool and platform geometry, generates heat maps, analyzes navigation with respect to multiple goal locations, and can be updated to accommodate future developments in spatial behavioral analyses. Given these features, Pathfinder may be a useful tool for studying how navigational strategies are regulated

\section{Open Peer Review}

Approval Status

1 2

version 2

(update)

15 Jun 2020

version 1

28 Aug 2019

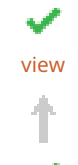

view

1. Matthew Holahan, Carleton University,

Ottawa, Canada

2. Robert McDonald ID, Canadian Center for

Behavioural Neuroscience, Lethbridge

University, Lethbridge, Canada

Nancy S. Hong, University of Lethbridge, Lethbridge, Canada

Any reports and responses or comments on the article can be found at the end of the article. 
by the environment, depend on specific neural circuits, and are

altered by pathology.

Keywords

search strategy, water maze, learning, memory, rodent, reversal, goal

\section{‘incf}

This article is included in the INCF gateway.

Corresponding authors: Matthew B. Cooke (matthew.cooke14@gmail.com), Jason S. Snyder (jasonscottsnyder@gmail.com)

Author roles: Cooke MB: Conceptualization, Formal Analysis, Methodology, Software, Writing - Review \& Editing; O'Leary TP:

Conceptualization, Investigation, Writing - Review \& Editing; Harris P: Software; Brown RE: Funding Acquisition, Resources, Writing -

Review \& Editing; Snyder JS: Conceptualization, Formal Analysis, Funding Acquisition, Supervision, Writing - Original Draft Preparation

Competing interests: No competing interests were disclosed.

Grant information: This work was funded by the Canadian Institutes of Health Research (JSS), the Natural Sciences and Engineering Research Council (JSS, REB), and the Michael Smith Foundation for Health Research (JSS, TPO).

The funders had no role in study design, data collection and analysis, decision to publish, or preparation of the manuscript.

Copyright: ( 2019 Cooke MB et al. This is an open access article distributed under the terms of the Creative Commons Attribution License, which permits unrestricted use, distribution, and reproduction in any medium, provided the original work is properly cited.

How to cite this article: Cooke MB, O'Leary TP, Harris P et al. Pathfinder: open source software for analyzing spatial navigation search strategies [version 1; peer review: 2 approved] F1000Research 2019, 8:1521 https://doi.org/10.12688/f1000research.20352.1

First published: 28 Aug 2019, 8:1521 https://doi.org/10.12688/f1000research.20352.1 


\section{Introduction}

All living organisms move throughout space to survive. Amongst mammals, there is a diversity of spatial behaviors that depend on numerous factors such as anxiety ${ }^{1,2}$, learning ${ }^{3}$, and the nature and pattern of stimuli that predict goals ${ }^{4-6}$. Given rodents' natural propensity to explore stimuli and environments, an array of rodent navigational tasks have been developed to investigate how various brain regions interact to control goaldirect behavior ${ }^{7}$. This has routinely been conducted using fixed-trajectory mazes such as the T-maze or radial maze. While these dry maze paradigms offer the convenience of fixed choice points that reduce ambiguity associated with classifying decisions and navigational responses, they cannot be used to study patterns of exploration in open environments.

A popular approach for studying free navigation in animals has been the water maze, where rodents learn the location of a hidden escape platform in a pool of water based on distal and/or local cue configurations ${ }^{3}$ Early studies validated the usefulness of the water maze for studying spatial processing and described progressive stages of learning where a rodent searches for the platform with increasing spatial specificity ${ }^{8,9}$. The vast majority of studies have since used escape latency or path length as primary measures of spatial learning. However, water maze navigation is unconstrained and animals can solve the task using different strategies that may not always differ in terms of the time it takes to reach the platform ${ }^{8,9}$. Thus, while latency and path length measures are convenient, they discard a rich amount of behavioral data.

Over the years, a number of groups have described manual and automated methods for classifying search strategies used by animals and humans in water maze experiments ${ }^{8,10-19}$. By mathematically relating the swim path to features of the maze environment one can identify and quantify the types of search strategies employed. Search strategy analyses have revealed that the ventral hippocampus is involved in coarse spatial goal-directed search ${ }^{16}$, that adult neurogenesis promotes spatially precise search ${ }^{20}$, and that spatially accurate search is reduced in humans with, and/or animal models of, Alzheimer's disease $^{21,22}$, autism ${ }^{23}$, traumatic brain injury ${ }^{22,24}$ and aging ${ }^{14,25}$. Despite the utility of these analyses they have been relatively uncommon to date, likely because commercially-available software packages often do not perform these analyses and the analytic methods used in previous work are not typically available in the form of an easy-to-use software package.

To facilitate the study of navigational search strategies, whether in the water maze or other 2-dimensional navigational paradigms, we created a new software application called Pathfinder. Pathfinder is a Python-based, open source tool with an intuitive graphical user interface and adjustable parameters for conducting detailed analyses of spatial search patterns. We validate Pathfinder with a mouse water maze dataset, where we find that male and female mice develop increasingly specific and direct spatial search strategies with additional days of training.

\section{Methods}

Installation and dependencies

Pathfinder is freely available under the GNU General Public License version 3.0.

Detailed instructions on use and installation of the program can be found on Github at github.com/MatthewBCooke/Pathfinder. We recommend installing Anaconda for Python 3, as it includes all of the following packages that are needed to run Pathfinder: PIL (https://pillow.readthedocs.io/en/latest/), xlrd (https://xlrd.readthedocs.io/en/latest/), numpy (https://www.numpy.org), pickle (https://docs.python.org/3/ library/pickle.html), scipy (https://www.scipy.org), matplotlib (https://matplotlib.org), and tkinter (https://wiki.python.org/ moin/TkInter). The MATLAB engine is optional and needs to be installed separately for entropy calculations (MATLAB and Statistics Toolbox Release 2018b, The MathWorks, Inc., Natick, Massachusetts, United States). Once Anaconda is installed, Pathfinder can be downloaded via Github or by typing "pip install pathfinder" in a shell window (i.e. Mac terminal or Windows command line). Pathfinder is then opened by typing "pathfinder" into the shell window and pressing return.

\section{General usage}

Pathfinder has a simple, user-friendly interface for extracting information from spatial navigation tracking files that contain xy coordinates over time (Figure 1). While it can be used to analyze multiple types of $2 \mathrm{D}$ navigational data, it is optimized for rodent spatial water maze experiments and accepts inputs from commonly-used commercial tracking software, including Ethovison (Noldus), Anymaze (Stoelting) and WaterMaze (Actimetrics). Pathfinder can also open files exported from the open source tracking software, ezTrack ${ }^{26}$, enabling a cost-effective and fully open source workflow for detailed water maze behavioral analyses. Trial information from these programs are outputted in CSV or Excel format, which can then be inputted into Pathfinder through the File menu. The experimental setup is specified in the main window (Figure 1a). Pathfinder can automatically calculate the position and size of the maze and the goal location (provided they are constant across trials), or these parameters can be entered manually.

Pathfinder relies on several variables that describe navigation relative to the pool and platform geometry: 1) Ideal Path Error (IPE): the summed error of the search path (Figure 1c). It is conceptually similar to the Cumulative Search Error (CSE) since it also measures proximity to the goal throughout the trial $^{9,27}$. An advantage of proximity measures is that they can distinguish two trials that have equivalent latencies/path lengths but differ in average distance to the platform. When calculating the IPE, the distance from the goal is measured at each time point in the trial and summed to generate a cumulative distance measure of the actual path (similar to CSE). In contrast to the CSE, the IPE is calculated by subtracting the cumulative ideal path distance from the cumulative actual path distance. The cumulative ideal path is simply the sum of all of the distances between the goal and the position of the 
a

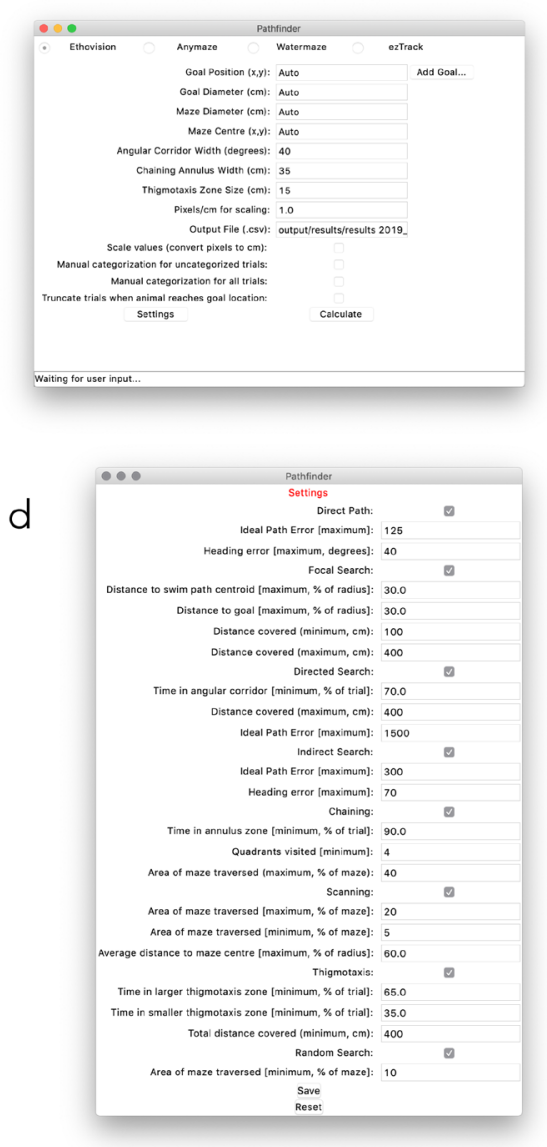

b
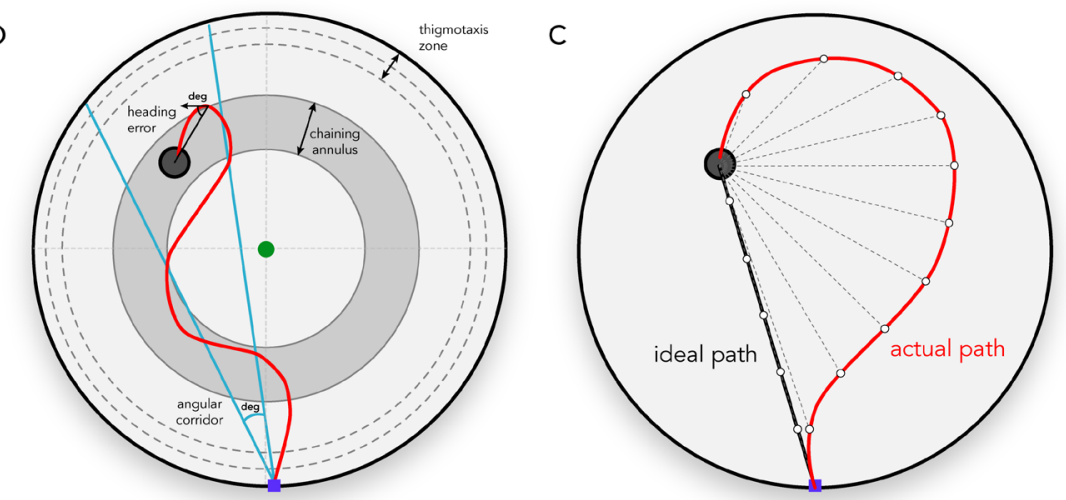

e

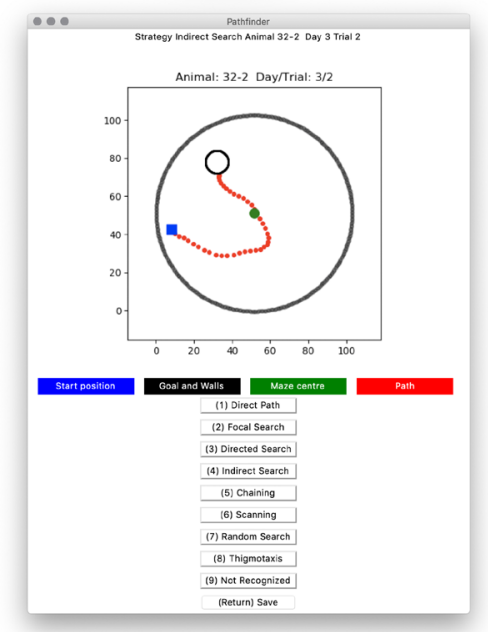

Figure 1. Graphical user interface and setting parameters. a) Screenshot of the main application window, where maze geometry is defined and input and output settings are established. b) Maze schematic and geometry for defining variables. The chaining corridor is centered on the goal platform and extends throughout all 4 quadrants; its width is specified in the main window. The larger thigmotaxis zone is specified in the main window; Pathfinder calculates the smaller thigmotaxis zone as half the width. Heading error is the angular distance between the actual path direction and a straight line to the goal (Pathfinder calculates average heading error at all points; only a single example shown). The angular corridor is used to define the directed search strategy, which depends on the accuracy of the animal's trajectory as it approaches the platform. The width of the corridor (in degrees) is specified in the main window and is centered on the goal. c) Schematic of the Ideal Path Error (IPE) metric. The distance from the platform is measured at each timepoint provided by the tracking software (actual path; only a fraction of distances shown for clarity) to provide a cumulative distance measure. Assuming the same swim speed as the actual path, distances are similarly summed from the ideal path, to provide a cumulative ideal path measure. The ideal cumulative distance is subtracted from the actual cumulative distance to generate the IPE. d) Parameter bounds are entered in the settings window. e) The manual categorization window, for viewing trial paths and manually categorizing strategies.

animal if it swam along a straight line to escape, using the average velocity from the trial. 2) Heading error: the angular distance between the current path and a straight line to the goal location. The current path direction is defined by a line connecting two temporally-adjacent xy coordinates. The average heading error is an average of all of the heading error values for the trial and the initial heading error is the average of the heading error values for the first second of the trial.

Additional variables are user-defined on the main window: 3) Angular Corridor Width: the size of the angular navigational corridor (in degrees) that extends from the start loca- tion and widens towards the goal, centered on the goal location. 4) Chaining Annulus Width: the width of the chaining annulus, a donut-shaped zone that is centered on the goal and spans all areas of the maze at a fixed distance from the maze wall. 5) Thigmotaxis zone size: the width of a zone that spans the perimeter of the maze and extends inward from the maze wall. Pathfinder also defines a "small" thigmotaxic zone that is half the width of this value. 6) Add goal: Pathfinder will perform all calculations and strategy analyses with respect to an unlimited number of goal locations. This can be used to measure performance and characterize strategies with respect to multiple goal locations (e.g. during spatial reversal, spatial 
choice). Selecting "truncate trials" will artificially end the trials if/when the subject reaches the additional goal locations. This is necessary, for example, to measure direct trajectories to a former goal location in a reversal paradigm (since the strategy will no longer meet direct path criteria if the former location in contacted and search continues elsewhere in the maze).

Once the variables are defined, boundaries must be set to establish the criteria for strategy categorization. Clicking "settings" will open up an additional window where strategy options can be selected and parameter bounds can be set (Figure 1d). Upon clicking "calculate", Pathfinder categorizes trials into one of eight search strategies that are ordered according to the degree of spatial specificity (high to low): 1) direct path, 2) focal search, 3) directed search, 4) indirect search, 5) chaining, 6) scanning, 7) random search, and 8) thigmotaxis. These categories are mutually exclusive and follow a defined order (1 to 8 ), but the user can opt to exclude strategies from the analysis. Thus, Pathfinder determines, in a stepwise fashion, whether a given trial fulfills the criteria for direct swim. If so, it moves on to categorize the next trial. If not, it determines whether the trial fits the subsequent strategy, and so on. The strategies and their parameters are shown in Figure 2. In the output file (.csv), each trial is categorized and the following additional metrics are provided: latency and distance travelled to reach the goal, average distance from the goal, percent of maze traversed, velocity, initial and average heading error and IPE. Pathfinder also has the ability to calculate the entropy for each trial, a measure of disorder in the path, relative to the goal location. The entropy calculation calls the MATLAB engine and requires a MATLAB license. Entropy measures the performance by looking at a shift from more disordered swimming (high entropy) to more spatially strategic paths (low entropy), and has been previously found to be highly sensitive to water maze search performance ${ }^{28}$. Due to the manipulation of large matrices, calculating the entropy of trials is very slow.

Occasionally, some trials cannot be categorized. The user therefore has the option to manually categorize uncategorized trials, by selecting this option on the main window. Additionally, there is an option to manually categorize all trials. Here, Pathfinder provides an image of the trial as well as shortcut keys to select the appropriate strategy. The software will also display the strategy it had automatically categorized for the

\section{Strategy}

1. Direct Path: a near perfect trajectory to the goal; minimal

deviation from a straight path.

\begin{abstract}
2. Directed Search: slight deviation from a direct
\end{abstract} path.

3. Focal Search: Search is spatially restricted and in the center portion of the maze.

\section{Parameters \\ IPE $<125$, average heading error $<35^{\circ}$

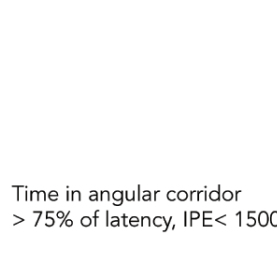 \\ Time in angular corridor
$>75 \%$ of latency, IPE $<1500$}
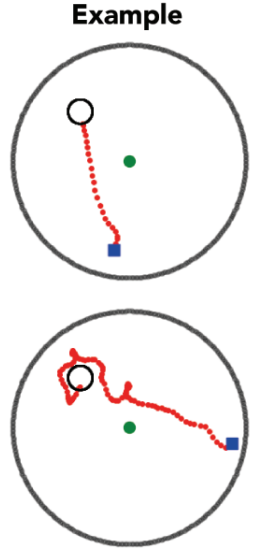

Average distance to swim path centroid $<30 \%$ of radius of maze, average distance to center of platform $<30 \%$ of radius of maze

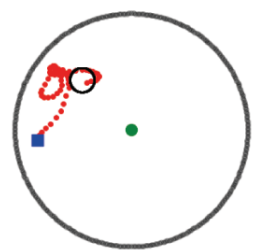

IPE $<250$, average heading error $<70^{\circ}$
4. Indirect Search: Search is spatially targeted but may contain $\sim 1$ major directional error.

\section{Strategy}

5. Chaining: Spatially non-specific \& searching a fixed distance from maze wall.

\section{Scanning: avoiding} maze wall but otherwise random.

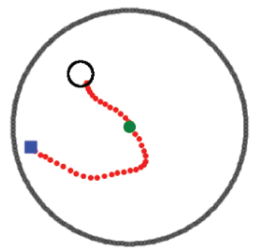

7. Random Search: no spatial search pattern.

\section{Thigmotaxis: swim path limited to maze} wall.
Parameters

Visits all 4 quadrants, time in annulus zone $>85 \%$ of trial average distance to center $<60 \%$ radius

Covers at least $10 \%$ of maze
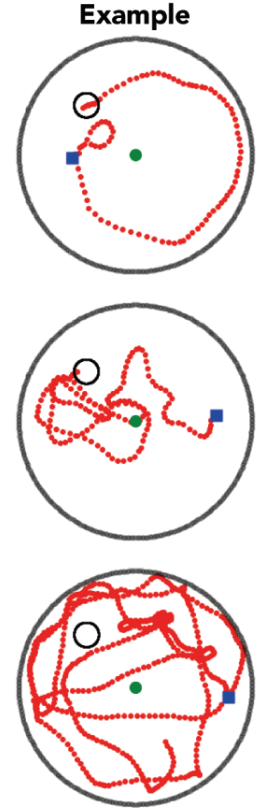

$35 \%$ of trial very close to wall $(7.5 \mathrm{~cm}), 65 \%$ of trial relatively close $(15 \mathrm{~cm})$

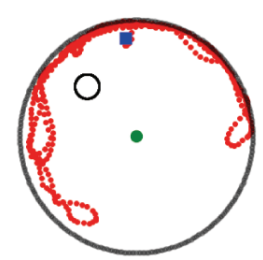

Figure 2. Search strategies and associated parameters. Pathfinder categorizes each trial according to 1 of 8 possible strategies. Categorization proceeds sequentially in the order shown (unless some strategies are excluded from the analysis). For example, for a trial to be classified as Random Search, the path must cover a minimum proportion of the maze and not fit any of the criteria for strategies 1-6. In the examples shown, the blue square indicates the start point and the green circle indicates the middle of the pool. Parameter settings are those used in the present study and should be adjusted depending on changes to testing procedures and maze geometry. 
displayed trial. Manual categorization will not overwrite the automatic categorization but will be displayed separately in the output file. This allows for comparison between the automatically calculated and user-selected strategy.

In addition to strategy categorization, Pathfinder will also create heatmaps as a useful visual representation of groups of trials. This is accomplished by counting the number of times animal(s) visit each bin in a hexagonal array that is overlaid on the maze (bin size is user-defined). The range of colors (cool to warm) can be automatically set to occupy the full scale. Alternatively, the user can manually set the maximum, above which all bins will read the hottest.

\section{Validation of Pathfinder}

Animals. A group of 35 C57BL/6J mice (18 male, 17 female) were used in this experiment (Jackson Laboratories, Bar Harbor, Maine). Relative to commonly-used samples sizes of 8-10 mice/group, a large cohort was used to maximize reliability and detect potentially infrequent strategies. Mice were housed in same-sex groups (2-4/cage) in polyethylene cages $(30 \times 19 \times 13 \mathrm{~cm})$ with pine chip bedding and a small tube and food and water available ad-libitum. Mice were housed under a reversed light-dark cycle (lights off 8:00am-8:00pm) and completed water-maze testing in the dark phase. Mice were first tested on the Barnes maze ${ }^{29}$ and were 18 weeks old when tested on the water maze for the current experiment. All efforts were made to minimize animal suffering, and all procedures adhered to guidelines from the Canadian Council on Animal Care and were approved by the Dalhousie University Committee on Laboratory Animals.

Spatial water maze training. The water maze consisted of a plastic circular pool $(110 \mathrm{~cm}$ diameter $)$ painted black. The pool was filled with water $\left(21-23^{\circ} \mathrm{C}\right)$, which was made opaque with the addition of non-toxic white tempera paint (Schola). A circular escape platform (14 cm height, $9 \mathrm{~cm}$ diameter) was positioned $1 \mathrm{~cm}$ below the water. The water maze was placed in a diffusely lit room with many extra-maze visual cues (posters on walls, a desk, the experimenter, geometric layout of testing room etc.).

Animals were tested over a total of 15 days. They first completed 8 days of acquisition training (A1-A8) with a hidden escape platform (4 trials/day). Across trials, mice were released into the pool from four different locations, with the order differing across mice. They were given a maximum of $60 \mathrm{sec}$ to locate the escape platform, after which they were guided to the platform by the experimenter. Mice remained on the platform for 15-20 seconds before being removed from the pool. During daily test sessions, mice were tested in squads of 4 and each mouse was held in separate cages filled with a bedding of paper towel. The inter-trial interval ranged from 2-8 minutes. The day following acquisition training, memory was assessed with a single 60 -sec probe trial with no escape platform present. Mice then completed a single day of re-training (Retrain) to reduce extinction that may occur during the probe trial. During re-training the escape platform is returned to the same location used in acquisition training.
After acquisition re-training, reversal learning was assessed over 3 days (R1-R3) with the escape platform moved to the opposite side of the maze. A reversal probe trial ( $\mathrm{R}$ probe) was then completed to assess memory for the location of the new escape platform location. Finally, a single day of visible platform training (Visible platform; 4 trials) was completed, where the escape platform was moved to a new location and made visible with the addition of a striped flag.

Behavior was recorded with the WaterMaze (Actimetrics) video tracking system (5 samples per second), via a camera placed directly above the pool.

\section{Results}

To validate Pathfinder, we trained mice for 8 days on a spatial water maze such that they achieved asymptotic performance according to standard metrics and should therefore have adopted distinct navigational strategies as they learned the procedural and spatial task demands. Following acquisition, mice received an unreinforced probe trial, 1 day of retraining, 3 days of reversal training (platform in opposite side of pool), another probe trial, and one day of visible platform training (outlined in Figure 3a).

To confirm that mice learned the task, we first analyzed performance using several metrics that indicate learning but do not reveal details about navigational strategies (Figure 3). We focused on acquisition and reversal phases since they are the main focus of our subsequent strategy analyses. Over the 8 days of acquisition, mice reached the platform faster, increasingly swam in the direction of the platform as measured by heading angle error and had lower IPE and entropy scores. The greatest performance improvements occurred during the first 4 days and, while all measures revealed improvements beyond day 4, only average heading error and entropy analyses revealed improvements beyond day 5. There were no sex differences in acquisition performance.

Reversal learning performance improvements were mostly apparent after the first day of training, likely because mice had learned the procedural aspects of the task and the spatial environment, and only had to learn a new platform location (Figure $3 \mathrm{~g}-\mathrm{k})^{30}$. Path entropy decreased from days 2-3, indicating continued learning. Females and males were equivalent in all performance measures except males had a lower initial heading error on day 1 of reversal training (Figure $3 \mathrm{~h}$ ).

Pathfinder revealed clear differences in search strategies over days of training (Figure 4). Over the first two days of acquisition, mice were initially thigmotaxic. After learning that the pool wall did not afford escape, they then transitioned to chaining, random and scanning search patterns, all of which indicate spatially non-specific search away from the pool wall. Over days 2-3 mice transitioned to spatially-specific forms of search, with $\sim 30 \%$ performing indirect searches to locate the platform. A similar proportion of trials were indirect searches over days $2-8$ of training. Mice increasingly displayed directed searches, focal searches and direct paths such that, by the end of training, search was spatially 


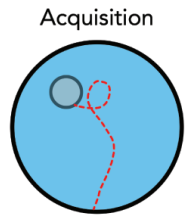

Days 1-8

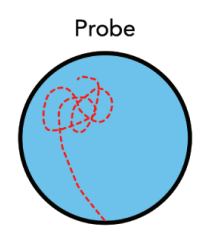

Day 9

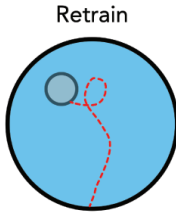

Day 10

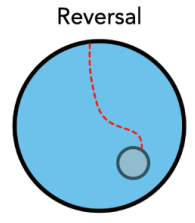

Days 11-13

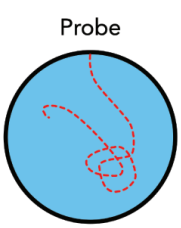

Day 14

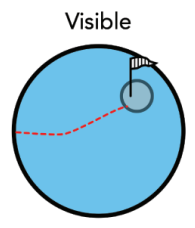

Day 15

Acquisition

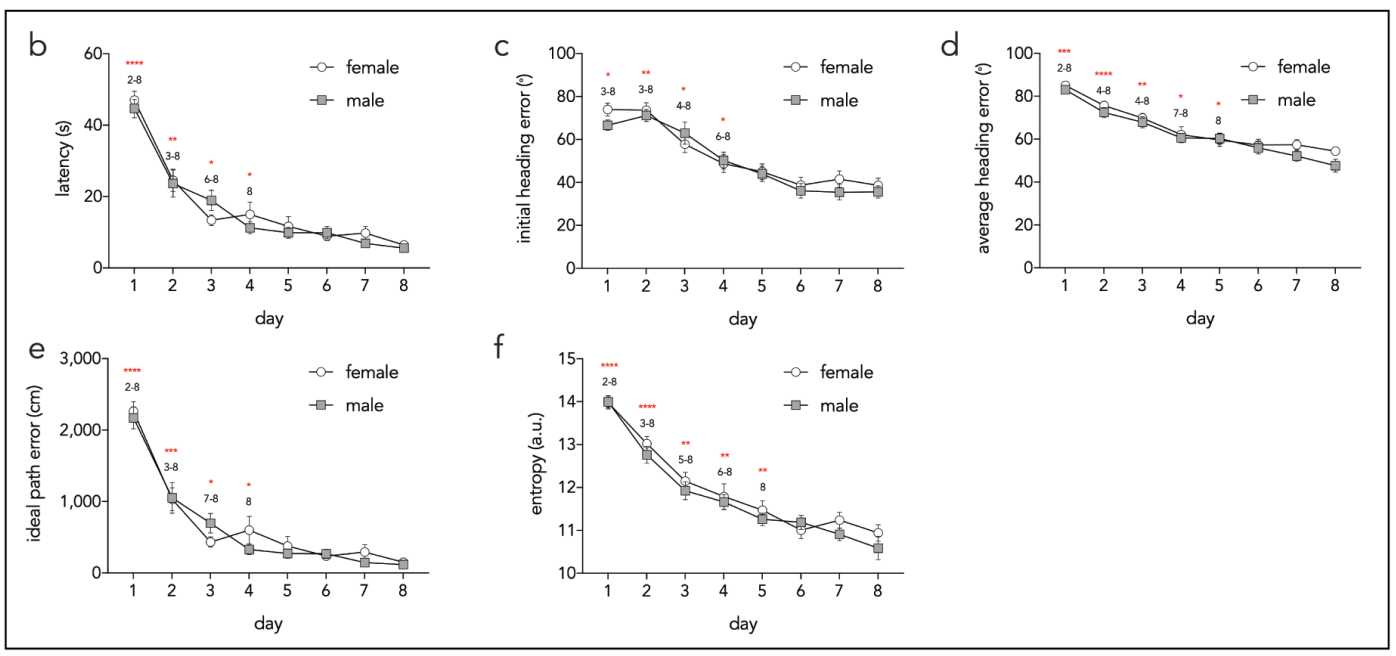

Reversal

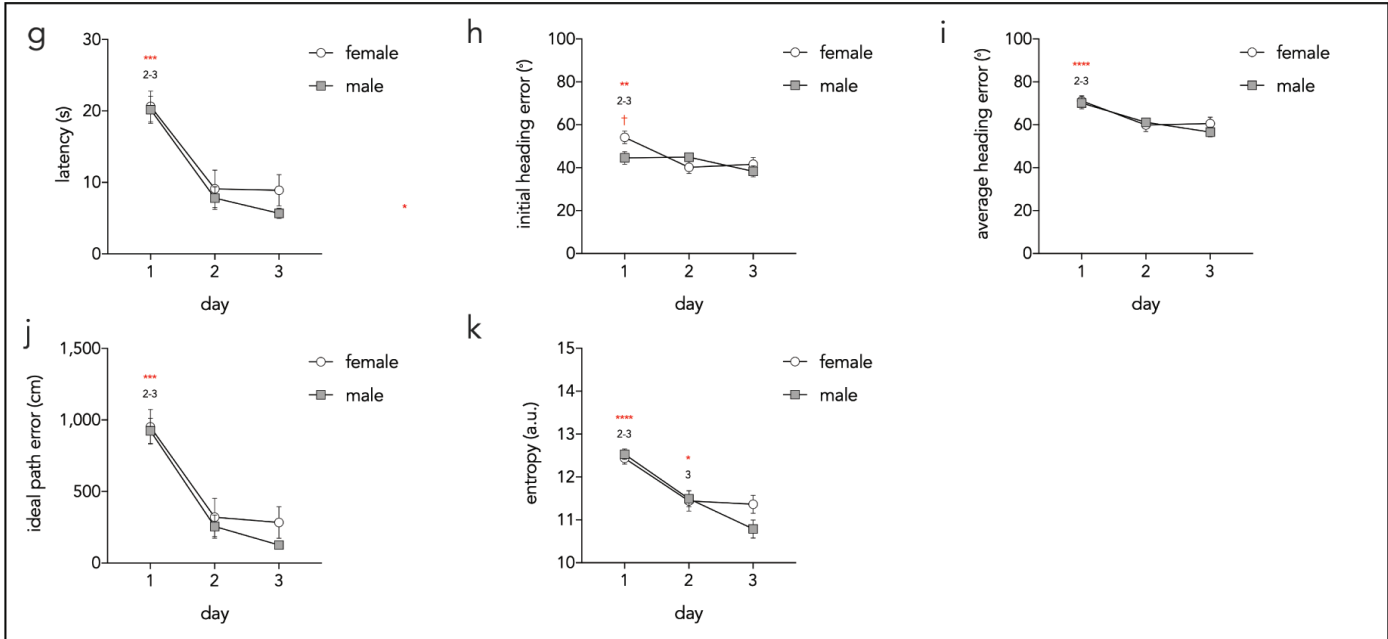

Figure 3. Acquisition and reversal performance as assessed by individual parameters. a) Schematic outline of full behavioral paradigm. Individual performance metrics were analyzed for acquisition $(\mathbf{b}-\mathbf{f})$ and reversal $(\mathbf{g}-\mathbf{k})$ stages of testing. $\mathbf{b})$ Latency to reach the platform decreased across days (day effect $F_{7.231}=75, P<0.0001$; sex effect $F_{1.33}=0.3, P=0.6$; interaction $F_{7.231}=0.9, P=0.5$ ). Asterisks denote statistically significant differences from the subsequent days that are indicated by the numbers. c) Initial heading error decreased over days (day effect $F_{7231}=39, P<0.0001$; sex effect $F_{133}=0.4, P=0.6$; interaction $F_{7231}=0.7, P=0.6$ ). d) Average heading error decreased over days (day effect $F_{7,231}^{7,231}=48, P<0.0001$; sex effect $F_{1,33}^{1,33}=2.5, P=0.12$; interaction $F_{7,231}^{7,231}=0.6, P=0.8$ ). e) Idea path error decreased over days (day effect $F_{7.231}=79$, $P<0.0001$; sex effect $F_{1,33}=0.3, P=0.6$; interaction $F_{7.231}=1.0, P=0.4$ ). f) Entropy decreased over days (day effect $F_{7.231}=75, P<0.0001$; sex effect $F_{1,33}=1.3, P=0.3$; interaction $F_{7,231}=0.5, P=0.8$ ). g) Latency decreased over days (day effect $F_{2.66}=69, P<0.0001$; sex effect $F_{1,33}=0.5, P=0.5$; interaction $\left.F_{266}=0.7, P=0.5\right)$. $\mathbf{h}$ ) Initial heading error decreased over days and was greater in females on day 1 (day effect $F_{266}=9, P<0.001$; sex effect $F_{1,33}^{2,66}=1.0, P=0.3$; interaction $F_{2,66}=4.7, P=0.01$ ). i) Average heading error decreased over days (day effect $F_{2.66}=21, P<0.0001$; sex effect $F_{133}^{1,33}=0.2, P=0.7$; interaction $F_{266}^{2,66}=0.9, P=0.4$ ). j) Ideal path error decreased over days (day effect $F_{2,66}=98, P<0.0001$; sex effect $F_{1.33}=0.5, P=0.5$; interaction $F_{2.66}=0.7, P=0.5$ ). k) Entropy decreased over days (day effect $F_{2.66}=39, P<0.0001 ;$; sex effect $F_{1.33}=0.6, P=0.4$; interaction $\left.F_{2.66}=2.6, P=0.08\right)$. ${ }^{2} P<0.05,{ }^{* *} \mathrm{P}<0.01$, ${ }^{* \star *} \mathrm{P}<0.001$, ${ }^{* \star *} \mathrm{P}<0.0001,{ }^{\mathrm{t}} \mathrm{P}<0.05$ within day, male vs female comparison. Symbols $=$ mean \pm standard error. 
a
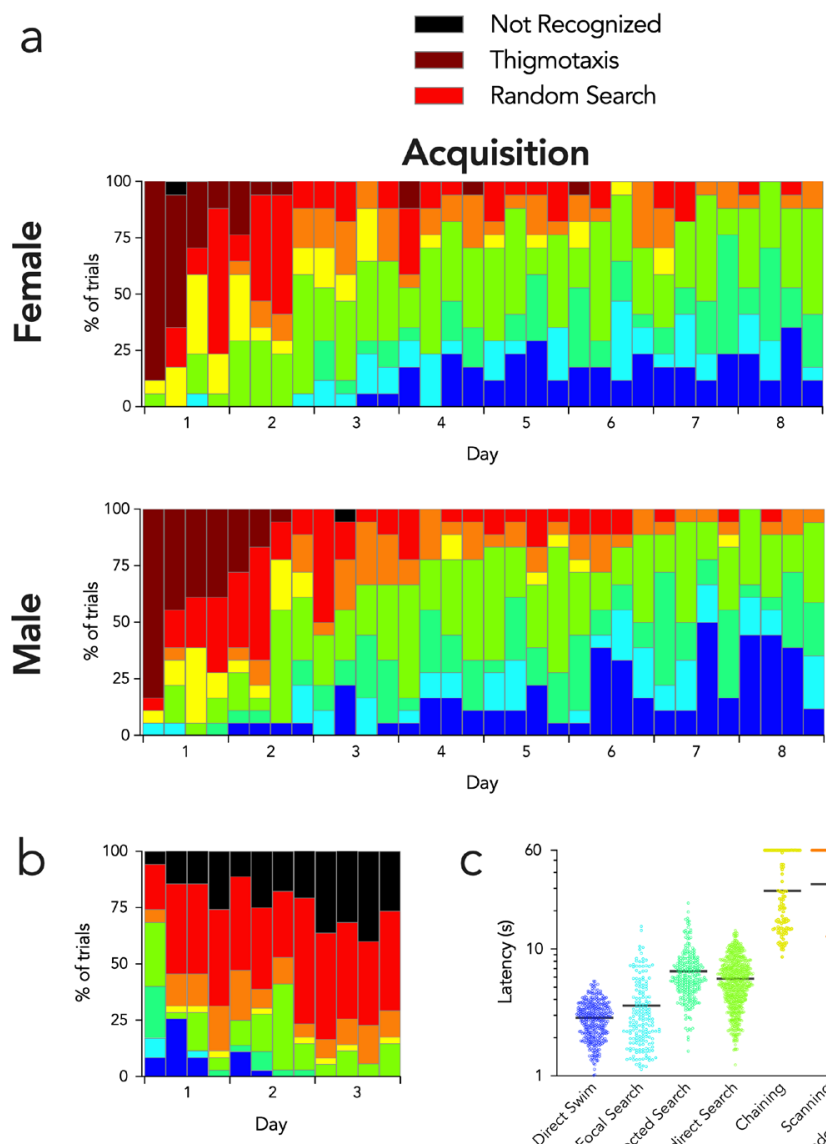

Day

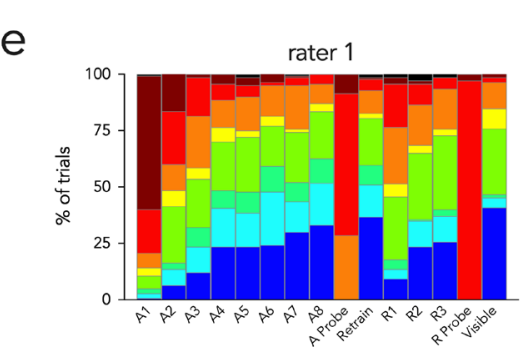

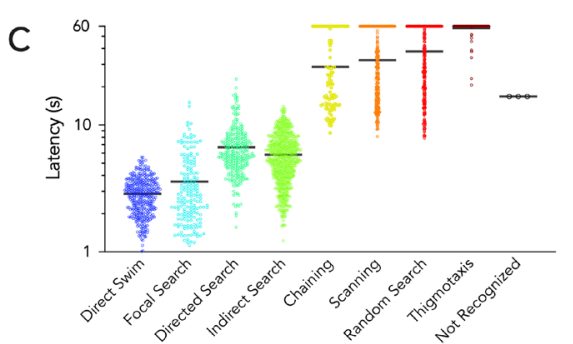

f

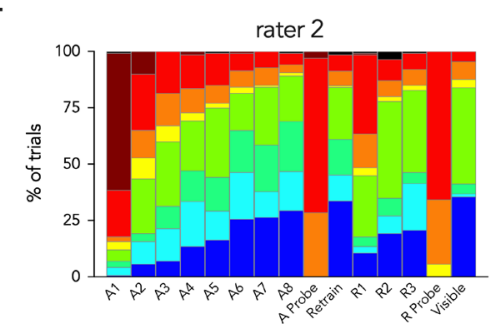

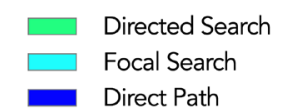
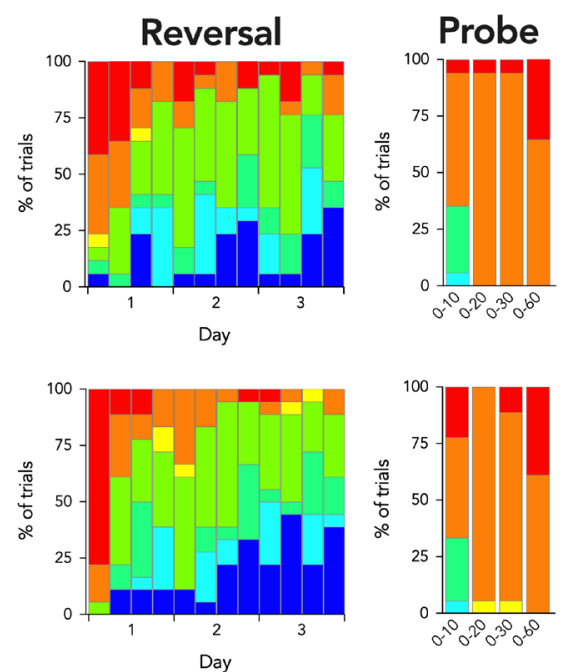

d
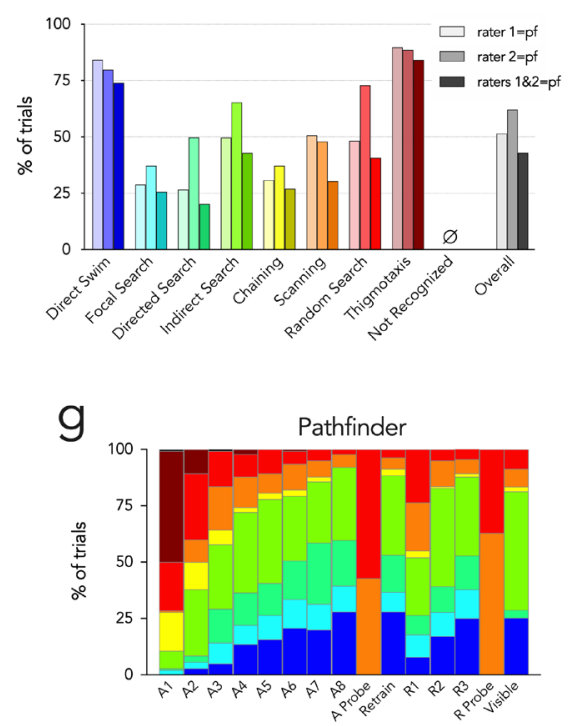

Figure 4. Pathfinder search strategy categorization of water maze performance. a) Search strategies for male and female mice. Each set of stacked bars indicates strategies used for the 4 acquisition and reversal trials for each day. Probe strategies are shown for the entire trial (0-60s) and for the first 10, 20 and 30s. b) Reversal strategies relative to the original platform location (indirect search excluded from analyses, since short swims that bypass the old location but quickly go to the new location become incorrectly classified as indirect searches with current settings). c) Escape latencies for all 1888 trials varied by strategy. Symbols indicate individual trials, bars indicate means (Kruskal Wallis test, $\mathrm{P}<0.0001$; Dunn's tests: direct path vs all others except focal search, $\mathrm{P}<0.0001$; focal search vs all others except direct path, $\mathrm{P}<0.0001$; directed search vs all others except indirect search, $\mathrm{P}<0.0001$; indirect search vs all others except directed search, $\mathrm{P}<0.0001$; chaining vs all others except scanning and random, $\mathrm{P}<0.01$; scanning vs all others except chaining and thigmotaxis, $\mathrm{P}<0.01 ;$ random vs all others except chaining, $\mathrm{P}<0.05$; thigmotaxis vs all others except random search, $\mathrm{P}<0.05)$. d) Manual vs automatic categorization. For each strategy assigned by Pathfinder, the proportion that received the same classification (manually) by 2 raters is shown. "Raters $1+2$ " indicates the percentage of Pathfinder classified-trials that also received the same classification by both raters. e) Search strategy classification by rater 1 for each day of testing. f) Search strategy classification by rater 2 for each day of testing. $\mathbf{g}$ ) Search strategy classification by Pathfinder for each day of testing.

specific on over $80 \%$ of trials. There were no major sex differences in strategy. The usefulness of strategy analyses (at least with default settings) for long probe trials is limited since spatially-specific strategies rely on IPE, which rapidly increases with trial duration. Additionally, animals will change strategies as they learn that the escape platform is not available in the expected location. Indeed, when the probe trial analysis was restricted to the first $10 \mathrm{~s}$, mice displayed focal 
and directed search strategies, indicating perseveration at the former platform location. When the analysis was conducted on longer segments, chaining was common, indicating that mice adopted a procedural strategy of searching in similar regions throughout the pool. Finally, when examining the entire probe trial, scanning and random searches dominated, indicating that mice eventually abandoned strategies that were no longer successful. During reversal, spatial specificity was initially very poor; mice primarily scanned, indicating preserved knowledge of the procedural requirements but no knowledge of the platform location. By the end of day 2 mice displayed levels of spatially-specific search strategies that were comparable to those at the end of the acquisition phase. Using the "add goal" feature, we also analyzed reversal strategies with respect to the original goal location (Figure $4 \mathrm{~b}$ ). This revealed a number of direct paths to the goal on the first day that quickly dissipated with additional trials as mice learning the new platform location.

To investigate possible relationships between strategy and conventional measures of water maze performance, we examined escape latencies for each strategy type, over all trials (1888 trials from all 15 days of testing; Figure 4c). Direct swim trials had the lowest latencies (2.9s on average) and was followed by the other spatially-specific strategies (focal search, 3.6s; directed search, 6.7s; indirect search, 5.8s). Non-specific strategies that avoided the pool wall were all significantly worse than the spatially specific strategies (chaining, 29s; scanning, 32s; random, 38s), and thigmotaxic trials were significantly worse than all other trial types (58s).

To determine how Pathfinder compared to subjective assessment of strategy, we compared Pathfinder categorization to manual scores generated by 2 independent raters (all trials). Rater 1 had experience in mouse behavior testing, but only brief training on water maze strategy classification. Rater 2 developed Pathfinder (MBC) and had extensive experience with strategy classification. Figure $4 \mathrm{~d}$ shows the proportion of Pathfindercategorized trials that received the same strategy classification via the manual raters. The greatest correspondence between automatic and manual categorization was seen for direct swims and thigmotaxis ( $80 \%$ for both). Automatic-manual consistency was much lower for the other strategies, ranged from $25-75 \%$ and differed for the 2 raters. Overall consistency between the 2 manual raters was $65 \%$. These data highlight the difficulty of intuitively differentiating complex search paths. Interestingly, when we averaged strategy analyses over all 15 days of testing, automatic and manual categorization resulted in similar patterns (Figure $4 \mathrm{e}-\mathrm{g}$ ). Thus, manual scoring is unreliable at the level of an individual trial, and human error can be masked when data are averaged.

To provide an intuitive visual inspection of search performance, we used Pathfinder to generate heatmaps of spatial occupancy at stages of testing that differed in spatial search patterns (Figure 5). Averaged over all trials and across sexes, mice swam in close proximity to the pool wall on day 1 of initial acquisition. By days 3 and 8 search was increasingly focused near the goal. Spatial preference was clearest on the probe trial, since these trials provided a longer temporal window to accumulate spatial occupancy samples. Day 1 of reversal testing resembled the probe trial, since mice spent the majority of time in the former platform location. By day 3, and on the probe trial, their spatial preference had shifted to the new, correct location. One set of heatmaps are presented using Pathfinder's auto scale feature, which maximizes the color range within a trial and can be useful for visualizing within-trial details since it avoids saturation. However, by differentially scaling, it can also obscure or inflate differences across trials. We therefore include a second set of heatmaps that are all scaled equivalently.

\section{Discussion}

Here we describe Pathfinder, an easy-to-use software package for analyzing patterns of spatial navigation. Pathfinder performs automatic classification of multiple search strategies that have been previously described in the rodent water maze, but it can also be used for analyzing navigational behavior in dry mazes, virtual mazes or any other environment where xy coordinates are provided. Currently, Pathfinder accepts inputs from three commonly-used, commercially-available tracking programs (Ethovision, Anymaze, Watermaze) and also the freelyavailable tracking software, ezTrack ${ }^{26}$. It requires no programming knowledge, but is open source and can be expanded by developers in the future. Using a mouse water maze dataset, we validated Pathfinder's performance and found that mice progressed through a series of search strategies that had increasing levels of spatial search specificity, consistent with earlier reports ${ }^{16-18,20,21,25,31}$. Mice initially displayed thigmotaxic, random and chaining search strategies as they learned the procedural components of the task. Pathfinder effectively demonstrated that mice transitioned to spatially-specific, presumably hippocampal-dependent, strategies during the later stages of training. Pathfinder also revealed the reverse transition from spatial to procedural to random strategies in the probe trial. By analyzing reversal performance with respect to multiple goal locations, Pathfinder showed that mice redirect their spatial search from the previously-reinforced platform location to the new location. Mice displayed a variety of search strategies on any given day, even after escape latency performance had plateaued. Since manual classification based on static images of swim paths was slow and inconsistent, Pathfinder may therefore be a useful tool for objectively characterizing swim strategies in the rodent water maze and 2D spatial navigation in other behavioral paradigms.

The water maze was initially described nearly 40 years ago and quickly became popular due to the ease of training, strong motivation for escape, and consistent reliance on hippocampal function ${ }^{3,32}$. Escape latency and path length were quickly adopted as the primary measures of learning and, due to their simplicity and sufficiency for many experimental situations, they remain the most commonly-used metrics. However, they cannot always differentiate between behaviors that vary in the degree of spatial bias. For example, animals that employ a chaining strategy search nonspecifically in some cases can reach the platform as fast as animals that perform a directed spatial search (Figure 4c). Latency and path length are also less 

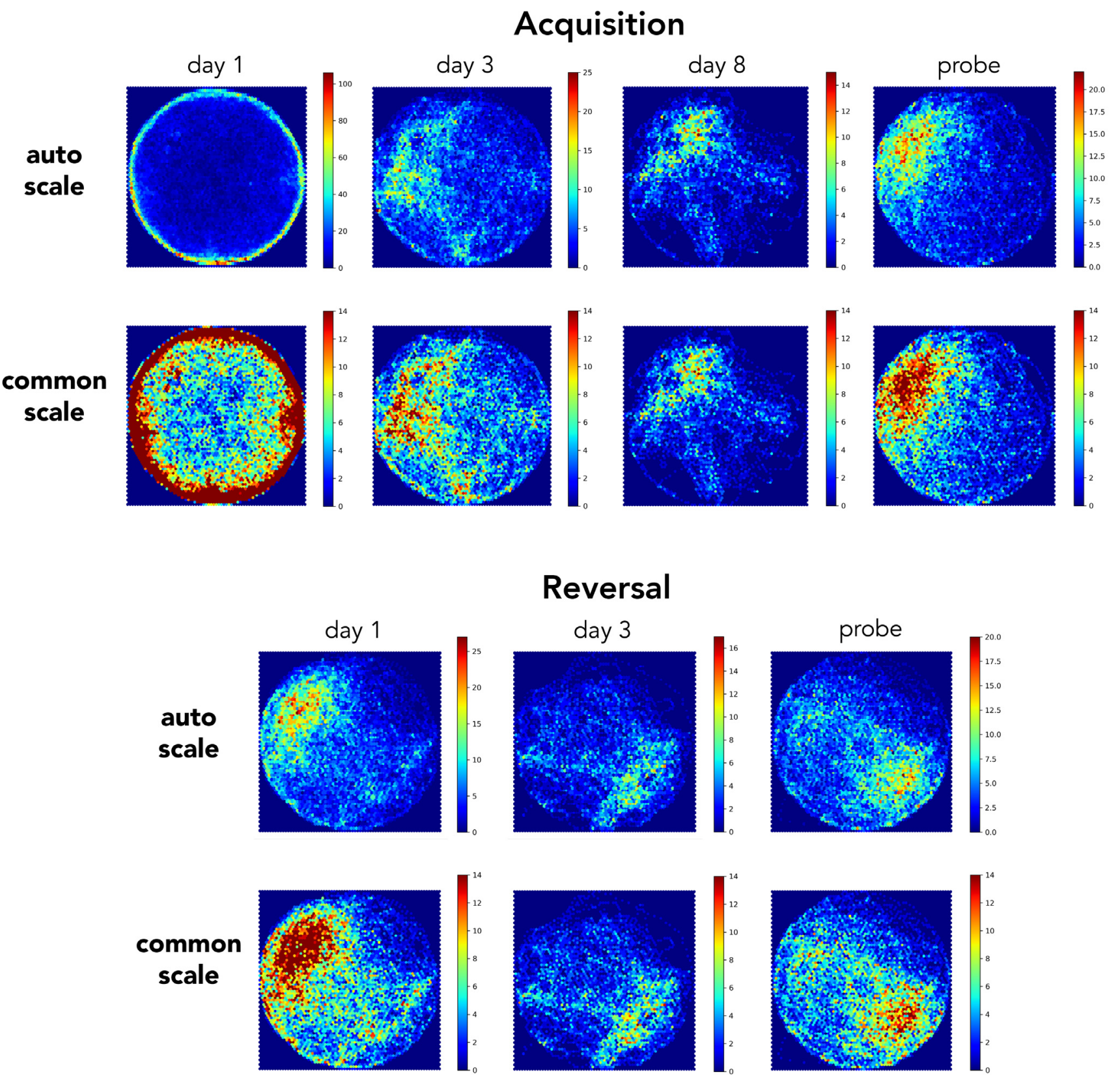

Figure 5. Heatmap visualization of spatial occupancy. Examples of heatmaps for various testing days (all trials from both sexes combined). Top rows: heatmaps were automatically scaled by Pathfinder, to occupy the full color spectrum and facilitate visualization of spatial occupancy within a given day. Bottom rows: heatmaps were set to a common scale, to facilitate comparison across days. Scale indicates number of samples within a spatial bin.

capable of detecting age-related impairments in spatial learning, prompting development of measures of proximity to the goal location, which has proven to be highly sensitive to group differences in both training and probe trial performance ${ }^{9,27,33}$. Our IPE proximity measure is similar to previous proximity measures with the exception that the cumulative ideal path distance is subtracted from the cumulative actual path distance to generate a path error measure. Finally, another recent metric that has been reported to be even more sensitive to group differences in spatial probe trial performance is entropy ${ }^{28}$. Entropy is originally a measure of thermodynamic disorder in a system but, when applied to the distribution of sampled sites in a maze, can also be used to measure the transition from high to low disorder in navigation, as animals focus their 
search on the precise goal location. By default, Pathfinder applies equal weighting to the path and goal components of the entropy measure and, compared to standard metrics, entropy was slightly better at detecting performance changes during the later stages of water maze acquisition.

Despite their convenience, even the most precise individual measures cannot distinguish between multiple possible strategies that an animal might employ to reach a goal location. Thus, strategy analyses may be valuable for identifying the role that different circuits play in guiding behavior. Consistent with the lower spatial resolution of ventral hippocampal place cells ${ }^{34}$, strategy analyses have found that the ventral hippocampus is particularly important for developing coarse, non-specific search patterns in the water maze and that increasingly spatially localized search depends on sequential recruitment of intermediate and then dorsal hippocampus ${ }^{16}$. Adult-born neurons are believed to promote memory precision and, indeed, blocking neurogenesis greatly reduced the adoption of spatially-specific search strategies ${ }^{20}$. Strategy analyses in animals have revealed spatial precision-related deficits in models of aging $^{25}$, stroke ${ }^{35}$, traumatic brain injury ${ }^{22,24}$, autism ${ }^{23}$ and Alzheimer's pathology $y^{21,22}$. With the advent of virtual reality, it has also become possible to test whether rodent water maze findings generalize to humans ${ }^{15}$. Indeed, hippocampal damage and CA1-specific lesions impair human water maze performance according to standard measures such as latency to reach the platform ${ }^{36,37}$. Human water maze experiments have also revealed superior spatial memory and greater spatial strategy use in younger individuals, and in males compared to females ${ }^{14}$. Here, we did not observe any sex differences, consistent with a recent meta analysis that revealed that male and female mice display broadly comparable performance in the spatial water maze ${ }^{38}$.

Given the apparent utility of strategy classification, the question arises as to why it has not been used more extensively. One likely explanation is that it is not a standard feature of commercially-available software packages, therefore requiring time and programming experience to execute. Groups that have performed strategy analyses have developed their own software, using either a predefined parameter-based approach, like ours, or machine learning algorithms that classify based on user input ${ }^{8,11,12,15-20,25,39}$. Since most previous approaches have not been developed into freely-available software packages, Pathfinder may enable more widespread adoption of strategy analyses. Moreover, in conjunction with freely-available tracking programs such as ezTrack (which is already supported) or others $^{39}$, users should be able to easily perform advanced navigation analyses at little cost.

It is worth noting that, with respect to water maze analyses, some behaviors (e.g. chaining and thigmotaxis) have been relatively well-described. In contrast, differences between spatially-specific search patterns (direct swim, directed search, focal search, indirect search) may be intuitive and quantifiable but the extent to which they are meaningful and result from distinct neural processes is less clear. Certainly, the fact that search strategies can now be easily quantified opens the door to future studies of the biology of complex navigation strategies. However, to some extent, strategy definitions are arbitrary, and it is therefore incumbent upon the user to determine which behaviors are relevant for their experimental paradigm.

\section{Future developments and additional uses}

One area where Pathfinder could be useful is for assessing spatial bias and choice behavior when there are multiple goal locations. Indeed, the water maze has been effectively used to study visuospatial goal discrimination ${ }^{40,41}$ and cue vs placerelated choice behavior ${ }^{42,43}$. We have recently used Pathfinder to show that neurogenesis promotes spatial platform preference in a spatial alternation water maze, which was detected by a greater number of direct swims when the platform was in the rat's preferred location than when it was in the nonpreferred location ${ }^{44}$. Neurogenesis-deficient rats often vacillated between the two platform locations, similar to vicarious trial and error behavior that has been described at choice points in dry mazes $^{45}$. Future software developments could possibly incorporate these types of movements between competing goal options to detect indecisiveness as animals refine goal-directed navigation behavior. Swim speeds are also currently not factored into Pathfinder's classification scheme, but could provide useful additional information for strategies that incorporate goal expectancy ${ }^{46,47}$ or a transition between place- and cue-directed navigation ${ }^{5}$. In the water maze, multiple platform locations $(>2)$ are typically only used in matching-to-place variants where it is expected that subjects quickly forget previous goal locations ${ }^{30}$. However, there is evidence that search patterns can reflect memory for many individual goal locations as well as the overall distribution of goals, at recent and remote post-training intervals, respectively ${ }^{6}$. Since Pathfinder can analyze navigation with respect to an unlimited number of goal locations, it may be useful for future investigations of how multiple spatial goals interact to guide search.

Spatial navigation and exploration have been studied in many paradigms and so it is worth reiterating that Pathfinder could be applied to study navigation by any species, in any open $2 \mathrm{D}$ environment, and not just the water maze. For example, it could be used to measure the spatial precision of homing behavior ${ }^{48,49}$, spatial preferences of mammals or invertebrates in novel environments $^{50-52}$, or navigation with respect to other environmental features that are known to drive firing of select populations of neurons, such as local and distal cues ${ }^{53}$, objects ${ }^{54,55}$ and environmental borders ${ }^{56}$. An array of virtual environments also opens the door to similar analyses of spatial navigation in humans ${ }^{36,37,57,58}$. Finally, eye tracking data, as humans and nonhuman primates explore $2 \mathrm{D}$ scenes, provides a measure of navigation that is analogous to rodent spatial exploration ${ }^{59}$. Indeed, hippocampal-damaged subjects display disorganized, inefficient search in a scene exploration task and are impaired according to several water maze-inspired metrics such as cumulative search error and heading angle error ${ }^{60}$. As a userfriendly application that can be further developed to accommodate differences between these various paradigms, Pathfinder 
may be a useful tool for characterizing complex spatial behavior and bridging findings across humans and animal models.

\section{Data availability}

Underlying data

Figshare: Raw data for "Pathfinder: open source software for analyzing spatial navigation search strategies", https://doi. org/10.6084/m9.figshare.9686987.v1 $1^{61}$

This project contains the following underlying data:

- Water maze output

- Pathfinder output

Data are available under the terms of the Creative Commons Attribution 4.0 International license (CC-BY 4.0).

\section{Software availability}

Software source code available from: https:/github.com/ MatthewBCooke/Pathfinder
Archived source code at time of publication: https://doi.org/ $10.5281 /$ zenodo. $3372762^{62}$

License: GNU General Public License 3.0.

Grant information

This work was funded by the Canadian Institutes of Health Research (JSS), the Natural Sciences and Engineering Research Council (JSS, REB), and the Michael Smith Foundation for Health Research (JSS, TPO).

The funders had no role in study design, data collection and analysis, decision to publish, or preparation of the manuscript.

\section{Acknowledgements}

The authors thank Sabri Snyder for contributing the name, Pathfinder, Kurt Stover for contributing initial work towards automatic strategy classification and Tian Rui Zhang for assistance with manual strategy classification. A previous version of this work is available from: https://doi.org/10.1101/715961
1. Kjelstrup KG, Tuvnes FA, Steffenach HA, et al.: Reduced fear expression after lesions of the ventral hippocampus. Proc Natl Acad Sci U S A. 2002; 99(16): 10825-10830.

PubMed Abstract | Publisher Full Text | Free Full Text

2. Bannerman DM, Deacon RM, Offen S, et al.: Double dissociation of function within the hippocampus: spatial memory and hyponeophagia. Behav Neurosci. 2002; 116(5): 884-901.

PubMed Abstract | Publisher Full Text

3. Morris RGM: Spatial localization does not require the presence of local cues. Learn Motiv. 1981; 12(2): 239-260.

Publisher Full Text

4. McDonald RJ, White NM: A triple dissociation of memory systems: Hippocampus, amygdala, and dorsal striatum. Behav Neurosci. 1993; 107(1): 3-22.

PubMed Abstract | Publisher Full Text

5. Hamilton DA, Rosenfelt CS, Whishaw IQ: Sequential control of navigation by locale and taxon cues in the Morris water task. Behav Brain Res. 2004; 154(2): 385-397.

PubMed Abstract | Publisher Full Text

6. Richards BA, Xia F, Santoro A, et al.: Patterns across multiple memories are identified over time. Nat Neurosci. 2014; 17(7): 981-986. PubMed Abstract | Publisher Full Text

7. Penner MR, Mizumori SJ: Neural systems analysis of decision making during goal-directed navigation. Prog Neurobiol. 2012; 96(1): 96-135. PubMed Abstract | Publisher Full Text

8. Graziano A, Petrosini L, Bartoletti A: Automatic recognition of explorative strategies in the Morris water maze. J Neurosci Methods. 2003; 130(1): 33-44. PubMed Abstract | Publisher Full Text

9. Gallagher M, Burwell R, Burchinal M: Severity of spatial learning impairment in aging: development of a learning index for performance in the Morris water maze. Behav Neurosci. 1993; 107(4): 618-626. PubMed Abstract | Publisher Full Text

10. Whishaw IQ, Jarrard LE: Similarities vs. differences in place learning and circadian activity in rats after fimbria-fornix section or ibotenate removal of hippocampal cells. Hippocampus. 1995; 5(6): 595-604. PubMed Abstract | Publisher Full Text

11. Wolfer DP, Madani R, Valenti $P$, et al.: Extended analysis of path data from mutant mice using the public domain software Wintrack. Physiol Behav. 2001; 73(5): 745-753.

PubMed Abstract | Publisher Full Text
12. Dalm S, Grootendorst J, de Kloet ER, et al.: Quantification of swim patterns in the Morris water maze. Behav Res Methods Instrum Comput. 2000; 32(1): 134-139.

PubMed Abstract | Publisher Full Text

13. Balschun D, Wolfer DP, Gass $P$, et al: Does cAMP response elementbinding protein have a pivotal role in hippocampal synaptic plasticity and hippocampus-dependent memory? J Neurosci. 2003; 23(15): 6304-6314. PubMed Abstract | Publisher Full Text

14. Schoenfeld R, Moenich N, Mueller FJ, et al.: Search strategies in a human wate maze analogue analyzed with automatic classification methods. Behav Brain Res. 2010; 208(1): 169-177.

PubMed Abstract | Publisher Full Text

15. Schoenfeld R, Schiffelholz T, Beyer C, et al:: Variants of the Morris water maze task to comparatively assess human and rodent place navigation. Neurobiol Learn Mem. 2017; 139: 117-127.

PubMed Abstract | Publisher Full Text

16. Ruediger S, Spirig D, Donato F, et al:: Goal-oriented searching mediated by ventral hippocampus early in trial-and-error learning. Nat Neurosci. 2012; 15(11): 1563-1571.

PubMed Abstract | Publisher Full Text

17. Vouros A, Gehring TV, Szydlowska K, et al:: A generalised framework for detailed classification of swimming paths inside the Morris Water Maze. Sci Rep. 2018; 8(1): 15089 .

PubMed Abstract | Publisher Full Text | Free Full Text

18. Illouz T, Madar R, Louzon $\mathrm{Y}$, et al.: Unraveling cognitive traits using the Morris water maze unbiased strategy classification (MUST-C) algorithm. Brain Behav Immun. 2016; 52: 132-144.

PubMed Abstract | Publisher Full Text

19. Rogers J, Churilov L, Hannan AJ, et al:: Search strategy selection in the Morris water maze indicates allocentric map formation during learning that underpins spatial memory formation. Neurobiol Learn Mem. 2017; 139: 37-49. PubMed Abstract | Publisher Full Text

20. Garthe A, Behr J, Kempermann G: Adult-generated hippocampal neurons allow the flexible use of spatially precise learning strategies. PLoS One. 2009; 4(5): e5464.

PubMed Abstract | Publisher Full Text | Free Full Text

21. Janus $C$ : Search strategies used by $A P P$ transgenic mice during navigation in the Morris water maze. Learn Mem. 2004; 11(3): 337-346. PubMed Abstract | Publisher Full Text | Free Full Text 
22. Brody DL, Holtzman DM: Morris water maze search strategy analysis in PDAPP mice before and after experimental traumatic brain injury. Exp Neurol. 2006; 197(2): 330-340.

PubMed Abstract | Publisher Full Text | Free Full Text

23. Faraji J, Karimi M, Lawrence C, et al:: Non-diagnostic symptoms in a mouse model of autism in relation to neuroanatomy: the BTBR strain reinvestigated. Transl Psychiatry. 2018; 8(1): 234.

PubMed Abstract | Publisher Full Text | Free Full Text

24. Tucker LB, Velosky AG, McCabe JT: Applications of the Morris water maze in translational traumatic brain injury research. Neurosci Biobehav Rev. 2018; 88: 187-200.

PubMed Abstract | Publisher Full Text

25. Gil-Mohapel J, Brocardo PS, Choquette W, et al:: Hippocampal neurogenesis levels predict WATERMAZE search strategies in the aging brain. PLOS One. 2013; 8(9): e75125

PubMed Abstract | Publisher Full Text | Free Full Text

26. Pennington $Z T$, Dong Z, Bowler R, et al:: ezTrack: An open-source video analysis pipeline for the investigation of animal behavior. bioRxiv. 2019 Publisher Full Text

27. Tomás Pereira I, Burwell RD: Using the spatial learning index to evaluate performance on the water maze. Behav Neurosci. 2015; 129(4): 533-539. PubMed Abstract | Publisher Full Text | Free Full Text

28. Maei $\mathrm{H}$, Zaslavsky $\mathrm{K}$, Wang $\mathrm{AH}$, et al.: Development and validation of a sensitive entropy-based measure for the water maze. Front Integr Neurosci. 2009; 3: 33. PubMed Abstract | Publisher Full Text | Free Full Text

29. O'Leary TP, Brown RE: Optimization of apparatus design and behavioral measures for the assessment of visuo-spatial learning and memory of mice on the Barnes maze. Learn Mem. 2013; 20(2): 85-96. PubMed Abstract | Publisher Full Text

30. Steele RJ, Morris RG: Delay-dependent impairment of a matching-to-place task with chronic and intrahippocampal infusion of the NMDA-antagonist D-AP5 Hippocampus. 1999; 9(2): 118-136.

PubMed Abstract | Publisher Full Text

31. Stone SS, Teixeira CM, Devito LM, et al:: Stimulation of Entorhinal Cortex Promotes Adult Neurogenesis and Facilitates Spatial Memory. J Neurosci. 2011; 31(38): 13469-13484.

PubMed Abstract | Publisher Full Text | Free Full Text

32. Morris RGM: The Watermaze. In The Maze Book. 2015; 94: 73-92 (Humana Press, New York, NY)

Publisher Full Text

33. Maei HR, Zaslavsky K, Teixeira CM, et al: What is the Most Sensitive Measure of Water Maze Probe Test Performance? Front Integr Neurosci. 2009; 3: 4 PubMed Abstract | Publisher Full Text | Free Full Text

34. Kjelstrup KB, Solstad T, Brun VH, et al.: Finite scale of spatial representation in the hippocampus. Science. 2008; 321(5885): 140-143. PubMed Abstract | Publisher Full Text

35. Woitke F, Ceanga M, Rudolph M, et al.: Adult hippocampal neurogenesis poststroke: More new granule cells but aberrant morphology and impaired spatial memory. PLoS One. 2017; 12(9): e0183463-16. PubMed Abstract | Publisher Full Text | Free Full Text

36. Goodrich-Hunsaker NJ, Livingstone SA, Skelton RW, et al.: Spatial deficits in a virtual water maze in amnesic participants with hippocampal damage. Hippocampus. 2010; 20(4): 481-491. PubMed Abstract | Publisher Full Tex

37. Bartsch T, Schönfeld R, Müller FJ, et al.: Focal lesions of human hippocampal CA1 neurons in transient global amnesia impair place memory. Science. 2010; 328(5984): 1412-1415.

PubMed Abstract | Publisher Full Text

38. Fritz AK, Amrein I, Wolfer DP: Similar reliability and equivalent performance of female and male mice in the open field and water-maze place navigation task Am J Med Genet C Semin Med Genet. 2017; 175(3): 380-391. PubMed Abstract | Publisher Full Text | Free Full Text

39. Gulyás M, Bencsik N, Pusztai S, et al.: AnimalTracker: An ImageJ-Based Tracking API to Create a Customized Behaviour Analyser Program. Neuroinformatics. 2016; 14(4): 479-81. PubMed Abstract | Publisher Full Text

40. Bannerman DM, Bus T, Taylor A, et al:: Dissecting spatial knowledge from spatial choice by hippocampal NMDA receptor deletion. Nat Neurosci. 2012 15(8): 1153-9.

PubMed Abstract | Publisher Full Text | Free Full Text

41. Arruda-Carvalho M, Sakaguchi M, Akers KG, et al:: Posttraining ablation of adultgenerated neurons degrades previously acquired memories. J Neurosci. 2011;
31(42): 15113-15127.

PubMed Abstract | Publisher Full Text | Free Full Text

42. McDonald RJ, White NM: Parallel information processing in the water maze: evidence for independent memory systems involving dorsal striatum and hippocampus. Behav Neural Biol. 1994; 61(3): 260-270.

PubMed Abstract | Publisher Full Text

43. Snyder JS, Cahill SP, Frankland PW: Running promotes spatial bias independently of adult neurogenesis. Hippocampus. 2017; 27(8): 871-882. PubMed Abstract | Publisher Full Text

44. Yu RQ, Cooke M, Zhao J, et al:: Adult neurogenesis promotes efficient, nonspecific search strategies in a spatial alternation water maze task. Behav Brain Res. 2019. PubMed Abstract | Publisher Full Text

45. Redish AD: Vicarious trial and error. Nat Rev Neurosci. 2016; 17(3): 147-159. PubMed Abstract | Publisher Full Text | Free Full Text

46. Hollup SA, Kjelstrup KG, Hoff J, et al:: Impaired recognition of the goal location during spatial navigation in rats with hippocampal lesions. J Neurosci. 2001; 21(12): 4505-4513.

PubMed Abstract | Publisher Full Text

47. Whishaw IQ Cassel JC, Jarrad LE: Rats with fimbria-fornix lesions display a place response in a swimming pool: a dissociation between getting there and knowing where. J Neurosci. 1995; 15(8): 5779-5788. PubMed Abstract | Publisher Full Text

48. Schenk F: A homing procedure for studying spatial memory in immature and adult rodents. J Neurosci Methods. 1989; 26(3): 249-258.

PubMed Abstract | Publisher Full Text

49. Maaswinkel $\mathrm{H}$, Jarrard LE, Whishaw IQ: Hippocampectomized rats are impaired in homing by path integration. Hippocampus. 1999; 9(5): 553-561.

PubMed Abstract | Publisher Full Text

50. Valente D, Golani I, Mitra PP: Analysis of the trajectory of Drosophila melanogaster in a circular open field arena. PLoS One. 2007; 2(10): e1083. PubMed Abstract | Publisher Full Text | Free Full Text

51. Eilam D, Golani I: Home base behavior of rats (Rattus norvegicus) exploring a novel environment. Behav Brain Res. 1989; 34(3): 199-211.

PubMed Abstract | Publisher Full Text

52. Dvorkin A, Szechtman H, Golani I: Knots: attractive places with high path tortuosity in mouse open field exploration. PLoS Comput Biol. 2010; 6(1): e1000638. PubMed Abstract | Publisher Full Text | Free Full Text

53. Leutgeb S, Leutgeb JK, Barnes CA, et al.: Independent Codes for Spatial and Episodic Memory in Hippocampal Neuronal Ensembles. Science. 2005; 309(5734): 619-623 PubMed Abstract | Publisher Full Tex

54. Tsao A, Moser MB, Moser El: Traces of Experiencein the Lateral Entorhinal Cortex. Curr Biol. 2013; 23(5): 399-405. PubMed Abstract | Publisher Full Text

55. Deshmukh SS, Knierim JJ: Representation of non-spatial and spatial information in the lateral entorhinal cortex. Front Behav Neurosci. 2011; 5: 69. PubMed Abstract | Publisher Full Text | Free Full Text

56. Solstad T, Boccara CN, Kropff E, et al.: Representation of geometric borders in the entorhinal cortex. Science. 2008; 322(5909): 1865-1868. PubMed Abstract | Publisher Full Text

57. Coutrot A, Silva R, Manley E, et al:: Global Determinants of Navigation Ability. Curr Biol. 2018; 28(17): 2861-2866.e4. PubMed Abstract | Publisher Full Text

58. Maguire EA, Nannery R, Spiers HJ: Navigation around London by a taxi driver with bilateral hippocampal lesions. Brain. 2006; 129(Pt 11): 2894-2907. PubMed Abstract | Publisher Full Text

59. Meister MLR, Buffalo EA: Getting directions from the hippocampus: The neura connection between looking and memory. Neurobiol Learn Mem. 2016; 134 Pt A: $135-144$

PubMed Abstract | Publisher Full Text | Free Full Text

60. Yee LTS, Warren DE, Voss JL, et al:: The hippocampus uses information just encountered to guide efficient ongoing behavior. Hippocampus. 2014; 24(2): 154-164.

PubMed Abstract | Publisher Full Text | Free Full Text

61. Cooke M, O'Leary T, Harris $P$, et al.: Raw data for "Pathfinder: open source software for analyzing spatial navigation search strategies". figshare. Dataset. 2019. http://www.doi.org/10.6084/m9.figshare.9686987.v1

62. Cooke M, Harris P: MatthewBCooke/Pathfinder: Zenodo Release for DOI (Version 1.1.6). Zenodo. 2019 http://www.doi.org/10.5281/zenodo.3372762 


\section{Open Peer Review}

\section{Current Peer Review Status:}

\section{Version 1}

Reviewer Report 21 January 2020

https://doi.org/10.5256/f1000research.22365.r56564

(C) 2020 McDonald $\mathbf{R}$ et al. This is an open access peer review report distributed under the terms of the Creative Commons Attribution License, which permits unrestricted use, distribution, and reproduction in any medium, provided the original work is properly cited.

\section{Robert McDonald}

Department of Neuroscience, Canadian Center for Behavioural Neuroscience, Lethbridge University, Lethbridge, AB, Canada

\section{Nancy S. Hong}

Department of Neuroscience, University of Lethbridge, Lethbridge, Canada

\section{Summary of the contribution:}

A recent paper submitted by Snyder and colleagues to F1000Research concerns the use of the Morris water task as an assay of learning and memory functions in the mammal. As noted 10 years ago, this is probably the most widely used assay of both spatial navigational processes and cognitive functions, in the rodent, in the history of psychology and behavioural neuroscience ${ }^{1}$. This paper introduces an open source analysis program, "Pathfinder", for assessing the traditional measures of spatial learning and memory, and also an evaluation of swim patterns/strategies that change in a systematic way during different stages of learning. The paper provides a brief historical account of the discovery and use of the Morris water task (MWT) suggesting that the earlier work lacked sophistication in their analysis of this complex cognitive/navigational behaviour, relying mostly on latency and path length. This is followed by a description of the new software including that it easily interfaces with commonly used tracking and behavioural analysis systems, and that it will be available for free. Both of these features will ensure that it can be used widely by scientists with varying ideas and views. Importantly, the authors provide "proof of principle" experiments highlighting its strengths at assessing the classic measures of place learning and memory, as well as the newer assessment of swim patterns during the different stages of acquisition and retention. The graphical user interface is excellent and allows the experimenter to determine the particular parameters of interest. A nice addition to this part of the paper was the verification of the data analysis completed by the new system as compared to several human observers, showing a high level of agreement. We also believe that having this software available to anyone interested in learning and memory processes in a variety of less constrained open-field situations will be very beneficial.

We would like to raise some issues for the readers and authors to think about relating to historical context, including early uses of swim pattern analysis, potential benefits and pitfalls of the swim 
pattern analysis, the nature of the representation acquired during task acquisition, and the possibility of future advances that might prove impactful.

\section{Historical context:}

It is important for the reader interested in using the MWT as a measure of learning and memory processes to get a better view of the history and development of the task which will place the new "Pathfinder" system in historical context. This exposition points to various empirical issues and theoretical questions that could be solved with future developments of the program. For example, the contributions of the "Lethbridge group" should be noted. In particular, Sutherland along with Whishaw and Kolb published some of the earliest lesion work using this task ${ }^{2,3}$. During this time, there was probably a significant amount of communication (see earliest papers and conference abstracts) between Morris and the Lethbridge group concerning the effects of fornix lesions, hippocampal ablations, and ultimately neurotoxins on the place learning version of this task. Sutherland went on to do important work using this paradigm investigating the subcortical and neocortical circuits implicated in this complex form of spatial navigation ${ }^{4,5}$. The Lethbridge group also contributed significantly to our understanding of the contributions of different neurotransmitters ${ }^{6}$, the important distinction between motor versus cognitive impairments ${ }^{7}$, the nature of the representation acquired during training ${ }^{8,9}$, etc.

The role of the HVS tracking system in making the MWT such an important tool for behavioural neuroscience and biomedical research should also not be forgotten. The two key labs (Morris and Sutherland) that contributed so much to the development of this task and understanding the brain systems and mechanisms involved used the HVS tracking system and then wrote their own data collection and analysis programs for use in their respective labs.

We also found in the paper, the general tendency to suggest that the early work was quite primitive and focused on latency and path length. I do not think this is accurate. If one looks at the early work by both groups, there was clear use of multiple parameters (latency, path length, heading angle, quadrant preference, thigmotaxia, rearing on the platform, wall and start-point revisits, and annulus crossings). This work was followed by assessment of different strategies used by rats following brain manipulations while acquiring the MWT. For example, rats with HPC lesions can show one successful strategy in which they learn to circumnavigate a certain distance away from the pool wall and run into the escape platform ${ }^{10}$. As well, other strategy changes have also been described following specific neuropharmacological manipulations ${ }^{11}$. The annulus crossings measure is interesting because it shows an early interest in spatial specificity of the place responses acquired following training on the MWT. The importance of this measure for understanding the neural basis of learning on this task was not clear at the time, but became evident when we were involved in addressing controversies over whether the HPC was important for learning this task or not ${ }^{12,13}$. The spatial specificity measure was an important part of our rebuttals to these claims ${ }^{14}$. Accordingly, we take significant credit for the idea that rats with HPC dysfunction can show a "place response" under some training conditions, but they do not show spatial specificity (but see Kolarik et al., 2018 ${ }^{15}$ ).

Devan and colleagues ${ }^{16,17}$ also used a swim path analysis to counter claims ${ }^{18}$ that the cause of impairments on the standard, spatial version of the water task, induced by brain manipulations (lesions, pharmacology, etc) were due to partial reinforcement effects and not because the subjects were unable to learn and remember the location of the escape platform. According to Gonzalez and colleagues ${ }^{18}$, the deficits in these experimental subjects were caused by the brain 
manipulations disrupting the supports of learning and memory (sensory, motor, and motivation) that resulted in the subjects finding the platform fewer times during training than a normal subject. We assessed these serious claims and showed that normal rats that received partial reinforcement on the spatial version of the water task showed impaired escape latencies. However, using a combination of time bin and zone analysis, we showed that the partially reinforced group went directly to the correct spatial location early in the trial and when they did not find it, swam to the pool wall. Note that the pool wall is also a source of reinforcement because the subject is removed by the experimenter at this barrier when a trial ends. Based on our analysis we concluded that, even under partial reinforcement training conditions, control rats learn the precise location of the escape platform, but other reinforcement contingencies also have an influence on their subsequent behaviour as the experimenter is also associated with escape from the pool.

We have also shown that rats can sequentially learn two different escape locations and during a probe test visit the most recent location first and then the old location ${ }^{19}$. It would be interesting if the authors discussed how the "Pathfinder" system could be used to capture these complex sets of swim strategies, in the different experiments described, and how bin analyses could be incorporated.

The authors of the current paper also describe vicarious trial and error (VTE) like behaviours exhibited when multiple locations are in play at the same time. In our experience, the most compelling demonstration of these kinds of competition-like behaviours is during the final test day following 12 days of cue/place learning ${ }^{20}$. When the cued platform was moved to a new spatial location and the subjects were started from an equidistant point between the old spatial location and the new cue location, some of the rats went to the new cue position and the others went to the old spatial location first. Interestingly, watching videos of the subjects during this competition test revealed some interesting patterns of behaviour. Some went directly to the cue, some went directly to the place, others started heading to one platform position and then switched direction, and some would change course several times of move their head back and forth to go back and forth before making a decision. We imagine this emerging when representations acquired by two parallel learning and memory networks are "flickering" back and forth in controlling the subject's behaviour ${ }^{21}$. Again, it is not clear from the manuscript how "Pathfinder" would pick up these kinds of micro-behaviours or the nature of further advancements in the program that might accommodate these more complex learning situations. Maybe a further expansion of this would be helpful in the manuscript.

\section{Potential benefits and pitfalls of the automated swim path analysis approach:}

As noted by the authors, it is not clear what the potential benefits of the swim path analysis produced by the "Pathfinder" system might be, and they provide some possible lines of research that might be fruitful. In our view, one area of enquiry that might be particularly fruitful is a reassessment of the learning and memory network centered on the HPC and the role of each of these areas (HPC, fornix, subiculum, thalamus, nucleus accumbens, mammillary bodies, prefrontal cortex, cingulate cortex, etc) to the different components of place navigation (strategies and strategy transitions). Another potentially interesting area of enquiry would be to revisit the contributions of various neurotransmitters including the ascending modulator systems as well as neurotransmitter systems localized in each sub-region. These lines of enquiry could be developed using both traditional as well as "state of the art" techniques including neurotoxic lesions, inactivation techniques, behavioural pharmacology, optogenetics, imaging, etc. 
Our experience with swim path analysis by human observers and comparing it to those generated by automated versions have been interesting. In a recent paper ${ }^{22}$, we assessed swim path strategies and transitions during the course of training on the spatial version of the water task based on early classic water task experiments and the approach taken by Ruediger and colleagues 23. We assessed the navigation response strategy used by rats during all training trials by viewing each swim and categorizing the behaviour. We replicated their findings that mice with ventral HPC lesions are impaired early in training and not later in training. Importantly, we also discovered some clear differences that are relevant to the "Pathfinder" program. In our experiment, the VHPC lesioned rats used general random search strategies in the early and middle stages of training, while the sham rats switched to direct search strategies towards the escape platform earlier. This switch to direct search strategies by control rats was earlier than control mice in the Ruediger experiments. As we have argued before, these kinds of species and potentially strain differences are important to be aware of when using these kinds of automated analysis systems ${ }^{22}$.

We found other potential caveats associated with these automated approaches. For example, for some individual swims, the criterion for a specific strategy either: did not categorize the subject's behaviour accurately; some swims could be categorized incorrectly; or no categorization fit the swim pattern exhibited. One of the most interesting examples we came across was late in training in which the swim strategies would be described as hybrid strategies. These include: thigmotaxia early in the swim and then a quick turn to the platform when the subject was close to the correct area of the escape location; circumnavigation but in zones A and B (HVS image); looping but with most time in zone $A$; single short looping behaviours to escape platform. The point of this simple analysis is that we understand the advantages of using automated algorithms for categorizing swim navigational strategies, but they have some disadvantages including missed strategies or swims categorized incorrectly. We strongly advocate that anytime a lab employs a new experimental manipulation (brain perturbation, strain, sex, age, etc) that swim navigational strategies are assessed with both automated and human observers.

\section{Nature of the representations used to navigate in the Morris water task:}

One final issue that is relevant to the "Pathfinder" analysis program is that it remains a bit of a mystery as to what the actual representation(s) and associated networks that guide behaviour during acquisition and retention of the spatial version of the water task.

Based on some experiments using the $\mathrm{MWT}^{9}$, it appears, somewhat counterintuitively that rats use the shape of the testing apparatus and directional information to locate the escape location. For these experiments, rats were trained on the standard, spatial version of the water task and then a probe trial was completed in which the maze was moved in the training context in a way that allowed the rats to either try to locate the escape platform via directional information or absolute spatial location information. The results clearly showed that a majority of the rats used a directional representation and not a representation of the relationships among the cues in the testing room. Our follow-up experiments assessing the implications of this work extended these results and showed that this directional representation seems to be based on pool shape information combined with head direction information encoded by the post-subiculum and related head direction network ${ }^{23}$. Even more striking, this directional representation transfers to new contexts, but the behaviours supported by this representation would be deleterious to performance unless the experimenter places the platform in the location based on directional information regardless of which context they are navigating. This is important to be aware of for 
various reasons, but particularly relevant in the current review because transferring to a new room will not result in random searches of the pool, as generally assumed. Rather, early on in training they will be swimming to a location that is now probably incorrect.

Finally, we implore researchers to ensure that during crucial probe (transfer) tests that the experimenter stir the pool water after each swim to ensure that olfactory cues are not supporting the place response ${ }^{13}$.

\section{Conclusions}

The Pathfinder program should prove to be a welcome addition to the toolbox available to researchers interested in the learning and memory processes involved in place navigation and the neural networks and mechanisms supporting these complex functions. Making it more accessible for scientists to look at various swim patterns during different stages of training will inevitably make it more mainstream to do so. In our view, further advancements to this new approach will increase its impact substantially.

\section{References}

1. McDonald RJ, Hong NS, Devan BD: The challenges of understanding mammalian cognition and memory-based behaviours: an interactive learning and memory systems approach.Neurosci Biobehav Rev. 2004; 28 (7): 719-45 PubMed Abstract | Publisher Full Text

2. Sutherland RJ, Kolb B, Whishaw IQ: Spatial mapping: definitive disruption by hippocampal or medial frontal cortical damage in the rat.Neurosci Lett. 1982; 31 (3): 271-6 PubMed Abstract | Publisher Full Text

3. Sutherland RJ, Whishaw IQ, Kolb B: A behavioural analysis of spatial localization following electrolytic, kainate- or colchicine-induced damage to the hippocampal formation in the rat.Behav Brain Res. 1983; 7 (2): 133-53 PubMed Abstract | Publisher Full Text

4. Sutherland RJ, Rodriguez AJ: The role of the fornix/fimbria and some related subcortical structures in place learning and memory.Behav Brain Res. 1989; 32 (3): 265-77 PubMed Abstract | Publisher Full Text

5. Sutherland RJ, Whishaw IQ, Kolb B: Contributions of cingulate cortex to two forms of spatial learning and memory.J Neurosci. 1988; 8 (6): 1863-72 PubMed Abstract

6. Sutherland RJ, Whishaw IQ, Regehr JC: Cholinergic receptor blockade impairs spatial localization by use of distal cues in the rat.J Comp Physiol Psychol. 1982; 96 (4): 563-73 PubMed Abstract | Publisher Full Text

7. Whishaw IQ, Tomie JA: Cholinergic receptor blockade produces impairments in a sensorimotor subsystem for place navigation in the rat: evidence from sensory, motor, and acquisition tests in a swimming pool.Behav Neurosci. 1987; 101 (5): 603-16 PubMed Abstract | Publisher Full Text 8. Whishaw IQ, McKenna JE, Maaswinkel H: Hippocampal lesions and path integration.Curr Opin Neurobiol. 1997; 7 (2): 228-34 PubMed Abstract | Publisher Full Text

9. Hamilton DA, Akers KG, Weisend MP, Sutherland RJ: How do room and apparatus cues control navigation in the Morris water task? Evidence for distinct contributions to a movement vector.J Exp Psychol Anim Behav Process. 2007; 33 (2): 100-14 PubMed Abstract | Publisher Full Text 10. Sutherland R, Dyck R: Place navigation by rats in a swimming pool.Canadian Journal of Psychology/Revue canadienne de psychologie. 1984; 38 (2): 322-347 Publisher Full Text

11. Whishaw IQ, O'Connor WT, Dunnett SB: Disruption of central cholinergic systems in the rat by basal forebrain lesions or atropine: effects on feeding, sensorimotor behaviour, locomotor activity and spatial navigation.Behav Brain Res. 17 (2): 103-15 PubMed Abstract | Publisher Full Text 12. Whishaw IQ, Cassel JC, Jarrad LE: Rats with fimbria-fornix lesions display a place response in a 
swimming pool: a dissociation between getting there and knowing where.J Neurosci. 1995; 15 (8): 5779-88 PubMed Abstract

13. Whishaw IQ, Jarrard LE: Evidence for extrahippocampal involvement in place learning and hippocampal involvement in path integration.Hippocampus. 1996; 6 (5): 513-24 PubMed Abstract | <513::AID-HIPO4>3.0.CO;2-J">Publisher Full Text

14. McDonald RJ, Hong NS: Rats with hippocampal damage are impaired on place learning in the water task when overtrained under constrained conditions.Hippocampus. 2000; 10 (2): 153-61

PubMed Abstract | <153::AID-HIPO4>3.0.CO;2-A">Publisher Full Text

15. Kolarik BS, Baer T, Shahlaie K, Yonelinas AP, et al.: Close but no cigar: Spatial precision deficits following medial temporal lobe lesions provide novel insight into theoretical models of navigation and memory.Hippocampus. 28 (1): 31-41 PubMed Abstract | Publisher Full Text

16. Devan BD, Stouffer EM, Petri HL, McDonald RJ, et al.: Partial reinforcement across trials impairs escape performance but spares place learning in the water maze.Behav Brain Res. 2003; 141 (2): 91-104 PubMed Abstract | Publisher Full Text

17. Devan BD, McDonald RJ: A cautionary note on interpreting the effects of partial reinforcement on place learning performance in the water maze.Behav Brain Res. 2001; 119 (2): 213-6 PubMed Abstract | Publisher Full Text

18. Gonzalez CL, Kolb B, Whishaw IQ: A cautionary note regarding drug and brain lesion studies that use swimming pool tasks: partial reinforcement impairs acquisition of place learning in a swimming pool but not on dry land.Behav Brain Res. 2000; 112 (1-2): 43-52 PubMed Abstract | Publisher Full Text

19. McDonald RJ, Hong NS, Craig LA, Holahan MR, et al.: NMDA-receptor blockade by CPP impairs post-training consolidation of a rapidly acquired spatial representation in rat hippocampus.Eur J Neurosci. 2005; 22 (5): 1201-13 PubMed Abstract | Publisher Full Text

20. McDonald RJ, White NM: Parallel information processing in the water maze: evidence for independent memory systems involving dorsal striatum and hippocampus.Behav Neural Biol. 1994; 61 (3): 260-70 PubMed Abstract | Publisher Full Text

21. Gruber AJ, McDonald RJ: Context, emotion, and the strategic pursuit of goals: interactions among multiple brain systems controlling motivated behavior.Front Behav Neurosci. 2012; 6: 50 PubMed Abstract | Publisher Full Text

22. McDonald R, Balog R, Lee J, Stuart E, et al.: Rats with ventral hippocampal damage are impaired at various forms of learning including conditioned inhibition, spatial navigation, and discriminative fear conditioning to similar contexts. Behavioural Brain Research. 2018; 351: 138-151 Publisher Full Text

23. Ruediger S, Spirig D, Donato F, Caroni P: Goal-oriented searching mediated by ventral hippocampus early in trial-and-error learning.Nat Neurosci. 2012; 15 (11): 1563-71 PubMed Abstract | Publisher Full Text

Is the rationale for developing the new software tool clearly explained? Yes

Is the description of the software tool technically sound? Yes

Are sufficient details of the code, methods and analysis (if applicable) provided to allow replication of the software development and its use by others?

Yes 


\section{Is sufficient information provided to allow interpretation of the expected output datasets and any results generated using the tool? \\ Yes}

\section{Are the conclusions about the tool and its performance adequately supported by the findings presented in the article?}

Yes

Competing Interests: I worked with the senior author (Snyder) when he was a graduate student and I was a faculty member at the University of Toronto in 2004/2005. The work on the functional significance of hippocampal neurogenesis resulted in a single publication.

Reviewer Expertise: Neural basis of learning and memory.

We confirm that we have read this submission and believe that we have an appropriate level of expertise to confirm that it is of an acceptable scientific standard.

Author Response 06 Jun 2020

Jason Snyder, University of British Columbia, Vancouver, Canada

Robert and Nancy - thank you for your detailed and thoughtful review. The additional background information and interpretations will be useful for those wishing to use Pathfinder when designing and analyzing their water maze experiments. We generally agree with the points you raise and would like to comment on a few of them specifically.

We understand that it may have sounded like we imply that early water maze work was primitive. We would like to clarify that we in fact tried to emphasize the opposite! Our take is similar to yours, which is that the early work by Morris, Sutherland, Whishaw etc performed quite extensive analyses which were essential to validate the water maze. Ultimately, as behavioral testing has become much more common, and since latency and path length are decent measures of basic performance, they soon dominated and detailed analyses became less common. Of course, even the early work did not conduct strategy analyses that are comparable to those offered by Pathfinder, but certainly the quality of those original papers cannot be understated. We have made some minor adjustments to the text to clarify our view.

You also raise some questions about how Pathfinder could be employed to detect strategies related to competing goals. We attempted to describe a few situations where rodents are tasked with deciding between spatial vs cued goals and multiple possible spatial goals. We cite these papers for the readers' reference and feel that these provide a good illustration of how the water maze can be used to study decision-making, conflict between multiple strategies/brain regions and the like. But the possibilities are endless and so ultimately it will depend on the creativity of the users.

We appreciate your comments about the importance of validating automated software with manual analyses. We agree that this is critical at the outset. Only when the user trusts their 
parameter settings should they proceed with the full analysis.

Finally, the issue of hybrid strategies is one that Pathfinder currently cannot address, unless one is willing to bin their trials prior to importing into Pathfinder. For a hybrid approach one may want to try the software described in Vourous, 2018, Scientific Reports since it can detect multiple strategies in a single trial.

Competing Interests: No competing interests were disclosed.

Reviewer Report 02 December 2019

https://doi.org/10.5256/f1000research.22365.r56738

(C) 2019 Holahan M. This is an open access peer review report distributed under the terms of the Creative Commons Attribution License, which permits unrestricted use, distribution, and reproduction in any medium, provided the original work is properly cited.

\section{Matthew Holahan}

Department of Neuroscience, Carleton University, Ottawa, ON, Canada

I agree with the authors that the assessment of spatial information processing in rodents with automatized tracking systems aids in the reliability of findings across studies and enhances efficiency in which one can make conclusions about specific manipulations. The current work, which would have been nice to include, would be more complete with:

1. A direct comparison to commercially available software - e.g., HVS Image provides similar tracking information so in this case, how do these two tracking systems fair head to head?

\section{A group of mice with hippocampal lesions.}

For point 2, does the tracking software pick out well-established deficits in spatial behavior following hippocampal lesions and does the new software provide any additional information on the deficits in spatial navigation produced by hippocampal lesions. I wonder also if the additional measures provided by this software will give more insight into spatial learning deficits in models where deficits were not noted; that is to say, conventional tracking software or output measures might not revealed a deficit when a deficit was predicted. Would this new software provide more robust measures to indicate deficits? Further work is required to more fully test the software to demonstrate its reliability.

Is the rationale for developing the new software tool clearly explained? Yes

Is the description of the software tool technically sound? Yes

Are sufficient details of the code, methods and analysis (if applicable) provided to allow 


\section{replication of the software development and its use by others?}

Yes

Is sufficient information provided to allow interpretation of the expected output datasets and any results generated using the tool?

Yes

Are the conclusions about the tool and its performance adequately supported by the findings presented in the article?

Yes

Competing Interests: No competing interests were disclosed.

Reviewer Expertise: Spatial learning and memory, Parkinson's disease, concussions, development, hippocampus, addiction

I confirm that I have read this submission and believe that I have an appropriate level of expertise to confirm that it is of an acceptable scientific standard.

Author Response 06 Jun 2020

Jason Snyder, University of British Columbia, Vancouver, Canada

Matthew - thank you for the feedback. Our response is a little delayed, because we have timed it to coincide with a software/manuscript update, which took longer than anticipated.

With respect to your points, we were unaware that any commercial software packages offer strategy-based analyses. There are some other free programs created by researchers, and it would definitely be interesting to do a comparison. It certainly would have been nice to validate it using an established model of hippocampal deficits, like a lesion. I do think it would pick up deficits that have been described, since hippocampal-lesioned rodents are typically thigmotactic and less spatially accurate, which Pathfinder clearly captures in the early stages of training in our experiment. We have validated it with neurogenesis-deficient rats (Yu, Behav Brain Res, 2019), where these rats displayed a strategy phenotype that was probably relatively subtle compared to hippocampal-lesioned animals. Finally, I do think it could be used to detect behavioral changes that other programs cannot. For this to work, it will be important for the user to understand their subject's behavior and adjust the parameters accordingly such that the strategies are captured. This will increase strategy detection accuracy and sensitivity but users always need to be cautious when interpreting the output, and assess whether finely-tuned parameters are detecting meaningful differences or not. In any case, there should be lots of existing navigational datasets out there that could be run with Pathfinder to address these exact questions. We look forward to seeing what people find.

Competing Interests: No competing interests were disclosed. 
The benefits of publishing with F1000Research:

- Your article is published within days, with no editorial bias

- You can publish traditional articles, null/negative results, case reports, data notes and more

- The peer review process is transparent and collaborative

- Your article is indexed in PubMed after passing peer review

- Dedicated customer support at every stage

For pre-submission enquiries, contact research@f1000.com 